\title{
Obstrucción de vía aérea por plegamiento de varilla metálica luego de IOT prolongada con tubo espiralado
}

\author{
da Rosa Sousa S. ${ }^{1,2}$, Voltolini G. ${ }^{1,2}$, Franck CL. ${ }^{1,2,3}$, Jardim de Melo R. ${ }^{3}$, Picolotto Moraes I. ${ }^{3}$ \\ 1 Hospital e Maternidade São José dos Pinhais, São José dos Pinhais, Brasil. \\ 2 Escola de Saúde Pública de São José dos Pinhais, São José dos Pinhais, Brasil. \\ 3 Hospital Universitário Evangélico Mackenzie, Curitiba, Brasil.
}

Introducción: El tubo endotraqueal espiralado (TEE) es un dispositivo para intubación que permite la ventilación invasiva durante una anestesia general. Se diferencia de un tubo endotraqueal convencional (TEC) por la presencia interna de un espiral de acero inoxidable, que refuerza la pared y dificulta el colapso. El TEE puede ser utilizado cuando existe riesgo de obstrucción del paso del flujo de gases por compresión o retorcimiento del tubo endotraqueal, durante procedimientos quirúrgicos orofaciales, neurocirugías o en posiciones quirúrgicas no supinas bajo anestesia general profunda. La escasez de informes similares en la literatura y la gravedad de un disturbio obstructivo agudo de un tubo endotraqueal dio origen a este informe de caso, que intenta orientar medidas preventivas y resolutivas, además de ser incluido en la lista de diagnósticos de causas de obstrucciones agudas de un tubo endotraqueal.

Informe de caso: Paciente masculino, 67 años, ASA 11, Mallampati 11l, sometido a nefrectomía izquierda en decúbito lateral derecho. Luego de inducción anestésica, durante la laringoscopia, se verificó la visualización glótica 3A de la clasificación de Cormack-Lehane. La Intubación Orotraqueal fue realizada con dificultad, utilizando un tubo endotraqueal espiralado número 8,0 (TEE-8.0). Sedación mantenida hasta el décimo día con grado RASS-2, cuando presentó asincronía con el respirador, reducción del volumen corriente, desaturación, aumento de la presión de pico y resistencia de vías aéreas, sugiriendo proceso obstructivo. Presentó hipoxemia grave y se optó por cambiar el TEE por TEC, solucionando el factor obstructivo. Se observó ruptura de la varilla metálica en el lugar exacto de contacto con el arco dentario.

Discusión: La utilización del TEE debe estar restringida al período transoperatorio bajo anestesia general profunda, en cirugías con riesgo de compresión o retorcimiento del tubo. Se recomienda que, una vez finalizado el procedimiento, el TEE sea sustituido por TEC, a fin de prevenir desenlaces desfavorables y potencialmente dañosos para el paciente.

Referencias:

1.Catane R, Davidson JT. A hazard of cuffed flexometallic endotracheal tubes. Br J Anaesth 1969; 17: 297.

2.Ball JE, Platt S. Obstruction of a reinforced oral tracheal tube. BJA: British Journal of Anaesthesia. 2010; 105(5): 699-700. DOI: https: //doi.org/10.1093/bja/aeq289

https://doi.org/10.25237/congresoclasa2019.03 